\title{
A saúde de homens presos: promoção da saúde, relações de poder e produção de autonomia
}

Male prisoners' health: health promotion, power relations and production autonomy

La salud de hombres presos: promoción de la salud, relaciones de poder y la producción de autonomía

Andréia Resende dos Reis*
Luciana Kind

\begin{abstract}
Resumo
O objetivo da pesquisa aqui relatada foi analisar as produções discursivas a respeito de saúde/doença expressas por homens presos que se encontram no regime fechado de execução da pena privativa de liberdade. O trabalho se desenvolveu em um complexo penitenciário de segurança máxima da Região Metropolitana de Belo Horizonte, Minas Gerais. Foram realizadas entrevistas semiestruturadas com 13 homens que desempenham atividades laborativas dentro da unidade prisional. $\mathrm{O}$ trabalho analítico se amparou na abordagem teórico-metodológica das práticas discursivas, permitindo a construção de três eixos de discussão: 1) os discursos produzidos sobre a saúde; 2) como os homens lidam com as práticas de cuidado no cotidiano; e 3) o que dizem sobre a perspectiva de mudança na oferta de saúde nas prisóes. As discussões sinalizam que o modelo hegemônico de constituição do masculino tem trazido consequências negativas para a saúde dos homens entrevistados, com resultados diretos para que se desenvolvam práticas de cuidado.
\end{abstract}

Palavras-chave: Sistema prisional. Masculinidades. Saúde do homem. Promoção da saúde.

\begin{abstract}
The aim of the research reported in this paper was to analyze the discursive productions about health/illness related to male prisoners within a deprivation of liberty regime. The research was developed in a maximum-security prison complex in the Metropolitan Region of Belo
\end{abstract}

\footnotetext{
Texto recebido em maio 2013 e aprovado para publicação em fevereiro de 2014.

Mestra em Psicologia pelo Programa de Pós-Graduação em Psicologia da PUC Minas, psicóloga da Fundação Hospitalar do Estado de Minas Gerais (Fhemig). Endereço: Rua Faisão, 235 - Barreiro, Belo Horizonte-MG. CEP 30624-080. Telefones: (31) 7570-7087/8614-9006.E-mail: deiares1@hotmail.com.

** Pós-doutora em Psicologia Social (UFMG), doutora em Saúde Coletiva (IMS/UERJ), professora no Programa de PósGraduação em Psicologia da PUC Minas. Endereço: Avenida Itaú, 525 - Bairro Dom Cabral, Belo Horizonte-MG. CEP 30535-012 Telefone: (31) 3319-4568. E-mail: lukind@gmail.com.
} 
Horizonte, Minas Gerais. Semi-structured interviews were conducted with thirteen men who are involved with labor opportunities within the prison unit. For the analysis, we relied on theoretical and methodological approach of discursive practices, allowing the construction of three lines of discussion: 1) produced discourses on health; 2) how men deal with care practices in everyday life; and 3) what they say about the prospect of change in the provision of health care in prisons. The discussions indicate that the hegemonic model that constitutes masculinity has had negative consequences on the health of the interviewed men, with direct consequences to the development of health care practices.

Keyword: Prison System. Masculinitiy. Male health. Health promotion.

\section{Resumen}

El objetivo de la investigación que presentamos aquí fue analizar las producciones discursivas acerca de la salud/enfermedad manifestada por hombres presos que se encuentran en cumpliendo de pena privativa de libertad. El trabajo se desarrolló en un complejo penitenciario de máxima seguridad de la Región Metropolitana de Belo Horizonte, Minas Gerais. Fueron aplicadas entrevistas semiestructuradas a trece hombres que realizan actividades laborales dentro de la unidad penitenciaria. El trabajo de análisis se basó en el enfoque teórico y metodológico de las prácticas discursivas, lo que permitió la construcción de tres líneas de discusión: 1) los discursos producidos sobre la salud; 2) cómo los hombres tratan las prácticas de cuidado en la vida cotidiana; y 3) lo que dicen acerca de la perspectiva de un cambio en la prestación de la asistencia sanitaria en las prisiones. Las discusiones indican que el modelo hegemónico de la formación de la masculinidad ha tenido consecuencias negativas para la salud de los hombres entrevistados, con consecuencias directas para que se desarrollen prácticas de cuidado.

Palabra clave: Sistema penitenciario. Masculinidades. Salud de los hombres. Promoción de la salud.

\section{Introdução}

- ste artigo apresenta resultados de uma pesquisa que teve por objetivo analisar as produçóes discursivas a respeito de saúde/doença expressas por homens presos que se encontram no regime fechado de execução da pena privativa de liberdade. Em virtude de traços de masculinidade fortemente arraigados na nossa cultura do homem universal (patriarca, viril, violento e dominador), e supostamente mais vulneráveis às influências desse cenário, 
que ora produzem e ora reforçam tais comportamentos, Gomes e Nascimento (2006) afirmam que há uma literatura vasta, focada principalmente em questionar e demonstrar como a "masculinidade hegemônica" gera comportamentos danosos à saúde.

No cenário brasileiro, e originalmente lançada como política de governo, está a Política Nacional de Atenção Integral a Saúde do Homem (PNAISH). Sua construção se deu sob a justificativa de que o modelo básico de atenção a quatro grupos populacionais, a saber, crianças, adolescentes, mulheres e idosos, não é suficiente para tornar o País mais saudável, por deixar de fora cerca de $25 \%$ da população brasileira: os homens de 20 a 59 anos (Brasil, 2008, p. 8).

Este trabalho não teve por finalidade a construção de uma análise detalhada da PNAISH. A revisão de literatura se deteve em trabalhos que articulam o conceito de gênero a essa política. O efeito do diálogo com os autores consultados produz uma inflexão crítica que nem sempre retoma a PNAISH em detalhes, o que fugiria ao escopo pretendido para este artigo.

Medrado, Lyra, Valente, Azevedo e Noca (2011) argumentam que, em termos de conteúdo, o texto da política baseia-se em um cenário descritivo e parcial sobre a saúde. Os autores assinalam que as informações sobre adoecimento e morte dos homens são reveladas em dados estatísticos e probabilísticos, além de serem apresentadas em uma leitura limitada sobre os determinantes sociais em saúde, marcados por gênero, classe, raça e idade. No que tange ao objetivo da PNAISH, ele se dá por meio de:

Promover a melhoria das condiçōes de saúde da população masculina do Brasil, contribuindo, de modo efetivo, para a redução da morbidade e mortalidade dessa população, através do enfrentamento racional dos fatores de risco e mediante a facilitação ao acesso, às açôes e aos serviços de assistência integral à saúde (Brasil, 2008, p. 38).

Medrado et al. (2011) argumentam que o objetivo geral da política é descrito de forma mais restrita, focando a saúde em aspectos de morbimortalidade, portanto, limitado para promover a melhoria das condiçôes de saúde da população masculina do Brasil. Portanto "[...] fala-se em agravos à saúde (resultado) e pouco sobre as condiçôes sociais que favorecem esses agravos (processo)” (Medrado et al., 2011, p. 4).

Nos textos governamentais, a PNAISH é apresentada com o propósito de qualificar a saúde do homem, pois se parte da premissa de que os homens não são sujeitos ativos no cuidado de sua saúde. O Plano Nacional de Ação da 
PNAISH para o triênio 2009-2011 preconiza que a política "[...] traduz um anseio da sociedade ao reconhecer que os agravos do sexo masculino constituem sérios problemas de saúde pública” (Brasil, 2009b, p. 3).

No texto da PNAISH, são resgatadas informações que enfatizam os altos índices de morbimortalidade de homens, representando verdadeiros problemas de saúde pública. No documento, a violência é um item importante que integra o diagnóstico do problema e aparece como um fenômeno difuso e complexo. Com relação a isso é pontuado que:

A integralidade na atenção à saúde do homem implica na visão sistêmica sobre o processo da violência, requerendo a desessencialização de seu papel de agressor, por meio da consideração crítica dos fatores que vulnerabilizam o homem à autoria da violência, a fim de intervir preventivamente sobre as suas causas, e não apenas em sua reparação (Brasil, 2008, p. 13).

Alguns autores nos dão pistas para a compreensão sobre o que se entende por vulnerabilidades dos homens. Souza (2005) pontua que a própria constituição do masculino contribui para comportamentos ditos danosos, pois os homens se utilizam de práticas e comportamentos para demonstrarem padrões hegemônicos de masculinidade, favorecendo as formas de adoecimento. Entre essas práticas, observa-se maior envolvimento em brigas, situações de homicídio (nas quais os homens ocupam o lugar de quem o realiza e quem é dele vítima), altos índices de acidentes de trânsito, envolvimento com o narcotráfico, uso de álcool e outras drogas e exposição a comportamentos sexuais desprotegidos. Esse "padrão", argumenta Souza (2005), justificaria o alto índice de encarceramento nesse grupo populacional.

De modo menos aderido à necessidade de justificar o aprisionamento de homens pelos seus "comportamentos de risco", Müller (2012, p. 2) se propõe a compreender como se produz "o homem que morre no Brasil" e na produção de um corpo masculino com estratégia biopolítica. Sobre esse corpo, "caro ao Estado", como expõe a autora, impõe-se "sua normalização pelo direito à vida e a contenção do excessivo de uma violência eminente e nomeadamente masculina" (Müller, 2012, p. 4). A autora sintetiza que a cartografia das doenças masculinas define os contornos de um corpohomem inscrito no campo da vulnerabilidade, do risco e da violência. Em suas palavras, a PNAISH contribui para a produção de "[...] um corpo masculino visível em seu caráter de fragilidade, vulnerabilidade e risco social, que tem sido a potência de uma engenhosa maquinaria de 
fazer cuidar para o homem viver" (Müller, 2012, p. 2). Evitar a morte antecipada seria a finalidade do Estado.

Numa alusão à PNAISH, as informações retratadas, produzidas e ilustradas em dados estatísticos, muitas vezes funcionam como dispositivos de controle do Estado para visibilizar um sujeito-alvo que lhe sirva de estratégias e mecanismos de ação. Quirino (2012) pontua que, ao se criar um protótipo ou modelo de sujeito, incorre-se seguramente em excluir outros sujeitos possíveis. Dessa maneira, na referida política, o homem anunciado ganha contornos trágicos, definidos não apenas pelos indicadores de morbimortalidade, mas também pelo seu grau de periculosidade social.

Portanto a política traz questôes complexas e paradoxais dos homens em relação à sua própria saúde e ao seu corpo, pois, conforme Carrara, Russo e Faro (2009), deriva em larga medida da posição que (ainda) ocupam na hierarquia de gênero. A questão não é de "cultura", segundo os autores, mas do modo como ela está imbricada ou implicada em relações de poder do discurso vitimário e paternalista incorporado à nova política. Dessa forma, para os homens, articular reivindicações com base em uma posição generificada e tornarem-se visíveis enquanto "homens" significa colocarem-se no mesmo plano que as mulheres, perdendo, assim, a posição de representantes universais da espécie e arriscando-se a perder também seus benefícios na hierarquia de gênero.

$\mathrm{Na}$ PNAISH, há um breve tópico intitulado "População privada de liberdade". A PNAISH reconhece que não existem informações sistematizadas sobre morbimortalidade nos ambientes prisionais, apostando em estudos que venham a evidenciar as condiçôes de saúde dessa população, que, de acordo com Brasil (2009a), está estimada em torno de 473.626 presos, sendo 95\% do sexo masculino. Dessa forma, este trabalho, em alguma medida, figura como uma contribuição para incrementar os estudos sobre saúde de homens presos.

Em uma revisão de estudos sobre saúde no sistema prisional, Gois, Santos Junior, Silveira e Gaudêncio (2012) constataram que a produção científica no Brasil é bastante recente, estando a primeira publicação datada de 2002, com apenas um artigo. No estudo, identificou-se que existe a predominância da abordagem quantitativa, com foco na identificação do perfil sociodemográfico e das condiçôes de saúde dos encarcerados: incidência de tuberculose, de infecção pelo HIV, hepatites virais e outras doenças sexualmente transmissíveis, uso de drogas como álcool, maconha, cocaína e drogas e transtornos mentais. Nesse sentido, não são apenas as causas citadas pelas quais os homens adoecem 
e morrem, mas as próprias condições sociais na estrutura do sistema prisional intensificam essas vulnerabilidades. A lista de situações desfavoráveis e de precariedade do sistema carcerário brasileiro é amplamente denunciada pela imprensa. A precariedade sumariza em superpopulação, violência, iluminação e ventilação naturais insuficientes e falta de proteção contra condições climáticas extremas, higiene pessoal e alimentação inadequadas, falta de acesso à água potável, serviços médicos deficientes entre outras. Já as denúncias dão conta de rebeliôes orquestradas por detentos, liberação irregular de presos, facilitação de fugas, facilitação de entrada de drogas, armas e celulares dentro das penitenciárias e, em contrapartida, suas apreensões. Esses são alguns dos fatores que aumentam a vulnerabilidade dos homens que cumprem pena. Nesse sentido, poderia afirmar-se que eles são duplamente vulneráveis: por serem homens e por estarem presos. É nesse cenário que o breve apontamento sobre homens presos que consta na PNAISH permitiria atuar.

Com o propósito de aprofundar a compreensão sobre o alcance da PNAISH, propõe-se uma aproximação com a promoção da saúde, que atualmente direciona suas discussões sobre as ações locais em saúde. Akerman (2005), em texto anterior à publicação do texto da Política Nacional de Promoção da Saúde (Brasil, 2006), afirma que a promoção da saúde compreende a dimensão da saúde como construção que se dá no espaço cotidiano da vida humana, buscando entender o ambiente como um território vivo, dinâmico e principalmente sendo o reflexo de processos econômicos, históricos e culturais. Assim, o autor afirma que o espaço cotidiano é um campo de ação privilegiado para melhorar a qualidade de vida, minimizar riscos e promover espaços saudáveis, podendo, por vezes, propiciar territórios de ação local de saúde.

Nessa perspectiva, aponta-se o estabelecimento prisional masculino como mais um cenário social para se pensar a promoção da saúde. Explorar esse cenário, considerando-o também como determinante do processo saúdedoença e incorporando os referenciais da promoção da saúde, é promover uma ampliação das discussões. A falta de se conhecer o cotidiano de cada preso, as formas de viver de cada um que habita naquele território, dos modos particulares de organização da vida social dentro de uma penitenciária, suas peculiaridades, apresenta-se hoje como uma lacuna na produção do conhecimento na área da saúde.

Alinhando-se as discussões da cena empírica em foco neste estudo, acreditase que é possível abordar a saúde de homens presos como práticas sociais, nos moldes cunhados por Foucault (1996, p.8): "[práticas] sociais podem chegar a engendrar domínios de saber que não somente fazem aparecer novos 
objetos, novos conceitos, novas técnicas, mas também fazem nascer formas totalmente novas de sujeitos e sujeitos de conhecimento".

\section{Metodologia}

Participaram da investigação 13 homens, com idades entre 20 e 64 anos. Foram critérios de inclusão: estar preso, em cumprimento de pena privativa de liberdade; residir em um mesmo pavilhão; desempenhar atividades laborativas intramuros em diversas oficinas de trabalho; estar de acordo com as condiçōes da pesquisa, formalizada mediante assinatura do termo de consentimento livre e esclarecida (TCLE). Idade, raça/etnia, opção sexual ou religiosa, os artigos da condenação e as penas a que foram condenados não compuseram critérios de inclusão.

A pesquisa foi brevemente apresentada nas oficinas de marcenaria, manutenção de freios, lavanderia, fábrica de cola, confecção de bolas, gesso, serviços de limpeza e horta, das quais participam presos que residem em dois pavilhões, denominados "pavilhões de trabalho". É importante destacar que a unidade prisional mantém 116 presos desempenhando atividades laborativas e remuneradas. Foi feito um convite coletivo em cada uma delas, anotandose os nomes dos presos interessados em participar, agendando-se os horários posteriormente com o núcleo de segurança.

A realização deste estudo foi respaldada pelos preceitos éticos vigentes para pesquisa envolvendo seres humanos. O projeto da pesquisa foi autorizado pela Secretaria de Estado da Defesa Social (SEDS) de Minas Gerais e posteriormente aprovado pelo Comitê de Ética em Pesquisa da Pontifícia Universidade Católica de Minas Gerais. Nas entrevistas com presos, foram observadas as diretrizes específicas reguladas pela SEDS, que exigem a presença de um agente de segurança, cumprimentos das normas e regulamentos locais, investigação sobre cadastro de antecedentes criminais, submissão aos procedimentos de segurança (revista em body scan e retenção de pertences), cumprimento de horários e permanência dentro da instituição prisional, intolerância a atrasos, adequação de comportamentos, evitação de contatos desnecessários com presos, vestimentas adequadas ao ambiente, acesso restrito nas dependências da unidade, proibição de celular e demais aparelhos digitais, proibição de gravações de imagens e voz, e utilização de prontuários somente com autorização do juiz da Comarca. Com um regime próprio de regras para a condução de pesquisa, esse contexto desafiou o trabalho de coleta de dados.

Como a pesquisadora estava impedida de gravar as entrevistas, as falas foram registradas em diário de campo, no qual foram anotados elementos 
ditos e percebidos durante as entrevistas, sempre que possível, com notas de falas e expressões as mais próximas possíveis do que os entrevistados expressaram. No diário também foram anotadas impressões e dúvidas, que posteriormente ajudaram na análise das entrevistas. As diretrizes da SEDS foram inicialmente experimentadas como um conjunto de restrições. Apesar de modularem o estudo, estas não impediram sua realização. Os homens entrevistados produziram falas para além daquelas marcadas pelo cotidiano prisional. Entre as perdas e ganhos, acredita-se que os dados produzidos foram ricos e as estratégias de registro e análise dos dados provavelmente não teriam sido as mesmas, nem tão intensamente debatidas e desenhadas no processo de trabalho. A produção discursiva acarretou elementos para além do roteiro $\mathrm{da}$ entrevista, trazendo à tona falas despretensiosas, provavelmente menos "arrumadas" do que muitas vezes o uso do gravador acaba por capturar. Cada entrevista teve duração de aproximadamente duas horas.

As anotações de entrevistas e reflexões do diário de campo foram transcritas. $\mathrm{O}$ material foi lido de forma exaustiva à procura de pistas que levassem à elucidação dos sentidos atribuídos à saúde e às práticas de cuidado. Para discussão dos dados obtidos, adotou-se o referencial construcionista, focalizando as práticas discursivas e produção de sentidos no cotidiano, filiadas a essa perspectiva. Nessa abordagem teórico-epistemológica das práticas discursivas, a investigação situa-se, sobretudo, nos processos pelos quais as pessoas descrevem e explicam o mundo em que vivem e a si mesmas (Spink \& Medrado, 1999). As questóes que compunham o roteiro de entrevista indagavam sobre a relação dos presos com a saúde antes de serem confinados e na situação de "privados de liberdade". Entre os temas que organizam as questôes estão: posicionamento pessoal sobre o que consideram uma "boa" saúde; práticas de cuidado com a própria saúde; busca por assistência à saúde; diferenças na procura de serviços por parte de homens e mulheres; e condições gerais de saúde na prisão.

\section{Resultados e discussões}

A partir da leitura do material transcrito, os dados foram reunidos em três possibilidades analíticas para:

a) os discursos produzidos sobre a saúde;

b) como os homens lidam com as práticas de cuidado no cotidiano; e

c) o que dizem sobre a perspectiva de mudança na oferta de saúde nas prisões. Essas possibilidades analíticas serão organizadoras da apresentação 
e discussão dos resultados da pesquisa. Para dar visibilidade às falas dos entrevistados, trechos das anotações das entrevistas serão utilizados em diálogo com leituras teóricas que alimentaram o estudo. Optou-se por não identificar as falas dos entrevistados, cujo local é de extremo controle, para preservação dos sujeitos envolvidos na pesquisa, de modo a evitar usos da pesquisa no bojo das tecnologias de poder que habitam o cenário da investigação. A inspiração para essa modalidade de apresentação dos dados vem da proposição de Reigota (1996, p. 52), que denomina como narrativas ficcionais a prática de "'embaralhar' fragmentos e criar 'colagens' que são estórias baseadas em fatos reais, mas que devem ser vistas/lidas como ficção". O embaralhamento aqui experimentado se dá pela não especificação dos entrevistados em cada um dos fragmentos de entrevista. Embora esse recurso não permita produzir falas situadas por trajetórias singulares, mantém-se a perspectiva de serem falas de homens presos, com inflexôes diferenciadas, como se tenta expressar ao longo da análise.

\section{Os discursos produzidos sobre a saúde}

Indagados sobre o que é saúde, alguns entrevistados constroem proposições que indicam uma concepção de saúde estabelecida por meio de nexos entre corpo, mente e espírito.

Acho que é dividido saúde mental, biológico e espiritual.

Saúde é o bem-estar fisico e mentalmente. Saber que os nossos órgãos estão

funcionando normalmente e mentalmente, sem nenhum distúrbio.

Harmonia dos sentidos: corpo, fisico e mente. Se tiver equilibrio, tem saúde, tem que manter a harmonia.

O trinômio do "bio-psico-social", somado à dimensão espiritual, propaga-se como sinônimo de boa saúde. Na Carta de Ottawa, documentochave nas discussões sobre promoção da saúde, lê-se a definição propagada pela Organização Mundial da Saúde (OMS), que toma a saúde como um "estado de completo um bem-estar físico, mental e social [...]" (Brasil, 2001). Bastante difundida, essa definição se especifica na discursividade dos "hábitos de vida saudáveis", diretamente mencionados por um dos entrevistados. No trecho de diálogo a seguir, observa-se que o entrevistado 
constrói uma descrição mais abrangente para o que entende por saúde, mencionando elementos que são fortemente difundidos como práticas de promoção da saúde:

Bem-estar da gente, de todo ser humano, uma vida saudável, uma alimentação saudável, hábitos saudáveis.

\section{Pesquisadora: O que você entende por hábitos saudáveis?}

Alimentação, se exercitar, higiene pessoal, ambiente limpo. Tem a parte psicológica, influencia muito. Principalmente pra gente que "tá" preso, é uma ansiedade, o convivio também... Tem de selecionar amizades e pessoas para conviver.

Outro entrevistado constrói proposições que conferem um sentido particular à possibilidade de "saúde mental": "Saúde... Se não fosse o cigarro... Quando a gente começa a pensar na casa, na família, aí fuma um cigarro."

Ironicamente, fumar um cigarro, ato execrado em qualquer cena de promoção da saúde, é visto e imbuído de sentido como ato de saúde. Nesse caso, fumar é estar vivo e poder pensar e imaginar enquanto fuma um cigarro. $\mathrm{Na}$ fala desse entrevistado, é possível perceber a ambivalência entre o uso que faz do cigarro e os riscos à saúde. Por um lado, a expressão "se não fosse o cigarro", como contraponto à saúde, sugere que os riscos desse hábito são considerados. Por outro lado, fumar permite-lhe "escapar" das opressōes do afastamento da família, da vida reconhecida como sua fora da condição de confinamento. É particularmente importante fumar quando começa a pensar na casa e na família, indica o entrevistado. Ao contrário de tomar essa mirada como apologia ao cigarro (não é nosso intento mergulhar no debate antitabagista e seus contrapontos), o enunciado nos coloca em diálogo com autores que acentuam a dimensão polissêmica da palavra risco (Castiel, 2007; Castiel \& Silva, 2006; Carvalho, 2004).

Castiel e Silva (2006) salientam que os estudos epidemiológicos sobre riscos, ao mesmo tempo em que se preocupam em estudar os riscos à saúde, reforçam dois grandes aspectos: o primeiro é o da moralização dos estilos arriscados de vida, que envolvem elevaçóes de riscos (estilos desregrados de vida) que podem veicular conotaçôes ligadas ao terreno do pecado ou da fraqueza de caráter. Assim, esse discurso ressalta a perspectiva racionalizada, expressão do puritanismo com conotaçóes ligadas ao comedimento, autocontrole, temperança e prudência. O segundo aspecto que o estudo do risco apresenta é o da responsabilização individual, cujo foco estaria voltado para o controle 
comportamental, desconsiderando os aspectos macrossociais, que, por vezes, estimulam as condutas chamadas de risco.

Com relação aos sentimentos sobre a própria saúde, um entrevistado explica:

Passar pelo que vivi, poderia estar numa cadeira de rodas, não tenho doença nenhuma, nunca usava preservativos. Não preciso de ninguém pra tomar conta de mim. Já fui alvejado várias vezes, nenhum me acertou, vivia na favela, nos piores conflitos durante nove anos, na minha adolescência, nunca "tive" tranquilo.

A explicação desse entrevistado traduz a influência dos aspectos culturais na masculinidade, reforçando as exigências dos modelos hegemônicos de masculinidades. Como observam Gomes e Nascimento (2006), as marcas identitárias trazem a crença de que se deve ser ativo, expressando-se em invencibilidade e invulnerabilidade, de se expor ao risco de forma viril, tendo como consequência a naturalização do descontrole sexual e a redução do exercício da sexualidade à penetração e à violência. Junto às ideias hegemônicas, justifica a capacidade de superação não só da dor, como também da morte.

Em relação aos repertórios sobre a saúde de outros homens, quando um entrevistado é indagado se as pessoas presas ali gozam de boa saúde, surge o seguinte relato:

Há presos que já estão há bom tempo presos, é natural que a doença apareça, a ociosidade faz aparecer doenças, estresse. Vejo pessoas deprimidas, cheias de manias, compulsivas, nossa... Tem demais. A própria vida, de viver na solidão forçada, leva a isso.

Tem muita gente doente. Principalmente pela idade, ai aparece as zicas. Não tem médico, não tem remédio, tem que rezar para não adoecer. Não vejo pessoas tristes, deprimidas. No meu pavilhão, todo mundo movimenta, distrai, sai pra trabalhar. Mas dizem que, nos outros pavilhöes, tem muita gente infeliz, doidas, debilitadas. Na verdade, no meu pavilhão também tem, a solidão adoece.

O "ficar parado", ser passivo, recolhido em sua solidão é experimentado como elemento que deprime, provoca doenças, estresse. As falas dos entrevistados sinalizam que o local é adoecedor, pois sentimentos de desesperança, longo tempo de confinamento, a situação vivenciada, a incapacidade para gerar soluçóes para seus problemas, uso de drogas, perda de recursos sociais, econômicos e vínculos familiares, culpa ou vergonha do delito são algumas explicaçóes para o aparecimento de transtornos mentais. 
Diante da questão sobre quem procura mais a assistência à saúde, se o homem ou a mulher, diz um entrevistado:

Acredito que seja a mulher. A mulher é mais complicada por vários fatores, né? A gravidez... Com o homem não tem esse problema. O homem é mais forte, a mulher é mais frágil, o homem aguenta mais o "batidão", a mulher não.

Pesquisadora: O que é "batidão"?

Serviço pesado, força fisica, e na criminalidade precisa disso.

Nesse fragmento, o entrevistado lança mão de ideias polarizadas para definir o ser homem em oposição ao ser mulher. Ensaia explicações para essas diferenças entre sexo/gênero, utilizando conteúdos relacionados tanto a aspectos biológicos quanto a culturais. Os argumentos produzidos e suas crenças reforçam a construção da masculinidade, apontando para as barreiras de cuidar de si.

O "batidão" se refere aos atributos associados ao homem, à invulnerabilidade, força física, coragem e violência. Essas características são demarcadas na fala do entrevistado, referindo-se ao par de oposição força/fraqueza, socialmente construídas e compartilhadas entre o sistema sexo/gênero. Percebe-se, em seu discurso, a construção em torno de valores tradicionais arraigados na construção das masculinidades, "na divisão sexual do trabalho" e do poder. $\mathrm{Na}$ sua visão, as mulheres estariam subordinadas aos homens, tendo seu espaço restrito ao ambiente doméstico, enquanto o homem vai para o trabalho, nesse caso para a criminalidade.

\section{Os homens e as práticas de cuidado no cotidiano}

Quando interpelado com a questão "o que você faz para cuidar da sua saúde?", emerge a necessidade de "ocupação da mente". Para um entrevistado, o trabalho é o principal meio para se ter êxito nessa empreitada:

Trabalho para manter o corpo no lugar, se não for assim, vou me entravar numa cama, na cela, ficar um velho gagá e aí vou me juntar com certos elementos e eu não quero, não. Se não trabalhar, não ocupar a mente... Se não ocupar a mente, começa a pensar coisas, ficar no barraco... Ai, eu gosto de trabalhar. A única coisa que faço para cuidar da minha saúde é trabalhando. 
Previa-se que o trabalho apareceria nas falas dos entrevistados, pois o convite para participação na pesquisa foi direcionado a presos que trabalham. Como discute Figueiredo (2008), o trabalho é uma categoria central e vital para a identidade masculina. Embora os entrevistados estivessem envolvidos em atividades laborais, isso não é suficiente para atenuar a condição de confinamento, vivida como adoecedora, como se reconhece em outros recortes de entrevista.

A relação estabelecida entre homem e trabalho é uma marca também do homem generificado nas relações sociais. Gomes, Nascimento e Araújo (2007) pontuam que, pelo fato de o trabalho constituir-se também numa função atribuída socialmente ao homem, a possibilidade de não se conseguir progresso no espaço laborativo ou a perda do emprego pode gerar tensões não somente econômicas, mas também de identidade. Os autores acentuam também que as atividades laborativas são tema de preocupações masculinas, e a busca por serviços de saúde, nesse caso, fica em um plano mais afastado. Sua fala também aponta que o "trabalho" é uma maneira de resistir e, de alguma forma, negociar o não envolvimento com "certos elementos", conformando sentidos muito particulares sobre o que se configura efetivamente como "riscos à saúde" de homens presos. O trabalho, portanto, para além das considerações dos autores que o abordam como um dos componentes da masculinidade hegemônica, expõe seu valor na "promoção da saúde mental" e na prevenção dos "riscos relacionais".

Outro entrevistado responde, de maneira mais concisa, à questão sobre cuidados com a própria saúde, enfatizando a falta de oportunidade para cuidar de sua saúde devido às condições de reclusão e de precariedade de recursos em que se encontra: "Nada. Não tem como fazer nada".

Observa-se que há uma predominância do modelo biomédico de atenção à saúde para esse entrevistado em particular. Sua entrevista dá a entender que ter saúde significa não estar doente: não se sentir doente, não ter aparência de doente e não necessitar de usar medicamentos. Esse modelo é apoiado, incorporado, praticado e fortalecido pelo contexto social, pelas indústrias farmacêuticas, pelas tecnologias médicas, por profissionais da área de saúde e por grande parte da população, inclusive a de baixa renda. No discurso desse preso, que tem por emblema o "não há nada a fazer", cuidar da saúde se restringe a práticas curativas. O sentimento de "não há nada a fazer" escancara a falta de oportunidade para cuidar da saúde devido às condições de reclusão e de precariedade de recursos em que se encontram, mas suprimem a possibilidade de se interpretarem práticas preventivas e promocionais como relacionadas à saúde. 
Nesse tópico do cuidado, foi feita a indagação sobre "o uso de preservativos nas relaçôes sexuais". Essa pergunta foi incorporada ao roteiro após as entrevistas iniciais, pois os preservativos eram constantemente mencionados pelos entrevistados nas expressóes "vivia muito louco, drogas, mulherada", apontando para marcações identitárias de masculinidades. Sobre essa perspectiva do cuidado, o fragmento de entrevista que se segue chama a atenção:

Nunca usei preservativo, aquilo ali é muito ruim, não é bom, não. É a mesma coisa que chupar bala com papel.

Pesquisadora: Já teve alguma doença?

Tive gonorreia [...]. Tomei uma medicação indicada por um "dono de uma farmácia lá do bairro". Não procurei o médico, não, fiquei com vergonha, aquilo é feio, doía na hora de urinar, tava com um pus e um cheiro ruim, fiquei com medo de perder meu órgão (risos). Tomei esses remédios e nada. Meu vizinho trabalha num posto de saúde, ele é agente de saúde, ai ele marcou uma consulta pra mim, ai tive que ir no médico, tomei os remédios que ele passou e ai sarou. Ele me falou que deveria usar preservativos, até me deu, mas eu nunca usei.

Nessa acepção, seu discurso tangencia a recusa de ir ao médico mesmo quando uma doença já está instalada e acaba também remetendo a sentimentos como vergonha e medo. E, ao procurar o médico, recebe um cuidado prescrito, definindo o modo de ser para esse homem, quando salienta: "Ele me falou que deveria usar preservativos, até me deu, mas eu nunca usei”. Com essas prescrições, basta se dedicar com afinco a controlar riscos provenientes de hábitos e comportamentos pouco saudáveis. Castiel (2012) comenta que riscos se constituem como imagens negativas. Para lidar com essa situação, os caminhos usuais preconizados pelas autoridades sanitárias apontam para práticas e ações de autocontrole e autocuidado: prevenir os riscos e aumentar a longevidade. Assim, utopia da saúde perfeita implica em controlar meticulosamente os riscos.

Outro sentido que se destaca desse fragmento é "Fiquei com medo de perder meu órgão". Conforme Figueiredo (2008), o pênis destaca o aspecto naturalizado do masculino, que constitui a base nuclear de sua identificação de gênero. Por essa característica, supostamente inata e imutável, o homem se reconhece sexualmente. Tal particularidade simboliza a virilidade e a autoafirmação esperadas de um homem. O autor defende que não é possível ignorar os significados da experiência corporal na interpretação cultural de gênero, fazendo com que tal experiência assuma um papel central para a 
construção das masculinidades e das feminilidades. Portanto perder o órgão aproximá-lo-ia do universo feminino. Ora, "[...] se falta esse atributo, o homem vê sua masculinidade ameaçada, correndo o risco de ser identificado com o feminino [...]" (Figueiredo, 2008, p. 151). Esse atrelamento entre sexo/gênero é alvo de debate no campo das teorias feministas (Butler, 2003). Contudo, mais do que contrapor a fala do entrevistado e uma perspectiva de crivo teórico que a explica, marca-se que o medo de "perder o órgão" e manter-se em "risco" (conforme se lê na peremptória afirmativa sobre o não uso de preservativos) alinha-se à configuração de um modo de viver a masculinidade: viril e invulnerável.

Considerando o período anterior da prisão, o discurso produzido sobre a busca por assistência à saúde reafirma o distanciamento do cuidado com a saúde: "Não costumava cuidar da minha vida. Vivia a cada dia como se fosse o último, só diversão, mulherada, drogas, curtição, amizades. Pensava que ia morrer, aquele era o último dia, por isso vivia loucamente".

O relato aponta os padrões de masculinidades socialmente construídos para afirmar sua crença acerca dos homens. Esse momento é visto quando se reporta a atividades ou características que julgam ser apropriadas para assinalar os homens. Por exemplo, ao se referirem a violência, virilidade e inconsequência.

Em contraste com os relatos anteriores, outro entrevistado, mesmo em situação de emergência, não buscou assistência mais adequada em razão menos da posição de uma masculinidade hegemônica, mas pela condição de uma vida "arriscada".

Fui baleado com três tiros: dois na perna direita e um na esquerda - ainda alojado (mostra). Não fui ao hospital, porque tinha que fazer ocorrência, senão ficava preso, eu já tinha oito mandados de prisão. Ai eu procurei uma colega que estudava veterinária e ela ficou com medo e não tirou as balas, eu mesmo que tirei [...]. Veja bem, igual um bicho. Bicho que vai no veterinário. No mundo do crime, a gente vira bicho.

Ele fala das práticas de cuidado possíveis num universo de submundo. Como prática discursiva, ele revela cenas de cuidado em condições de sobrevivência limítrofes. Como se vê, a questão da violência e das práticas marginalizadas está sempre em pauta, fazendo conexões com as histórias de vida de cada um, em maior ou menor medida. Os segmentos mais excluídos da população mostram uma relação de proximidade com a violência. $\mathrm{O}$ contexto de violência agudiza as vulnerabilidades a que esses homens estão expostos. Há uma interdição no acesso a recursos de saúde, já que procurar os serviços significa oferecer-se para a tutela do Estado no sistema prisional. 


\section{A oferta de saúde nas prisões}

Uma das questôes formuladas durante as entrevistas se interessava pela produção discursiva sobre a mudança local, buscando-se cenários imaginados para se empreenderem melhores práticas de saúde. Portanto os presos foram indagados: "O que você acha que precisaria mudar aqui na penitenciária para melhorar a sua saúde?”. O fragmento a seguir foi uma das respostas a essa pergunta:

Melhores profissionais, equipamentos, vontade política. Um profissional de Educação Física. Aqui, se eu arrumo uma corda para pular, o agente toma, me "caneta", diz que vou fazer uma teresa; ${ }^{1}$ se eu faço um pesinho na cela (colocar água na garrafa pet), fala que é arma, ai fica dificil.

Aponta-se a inventividade para se criarem práticas promocionais que atendam à prática de atividades físicas, tão largamente estimuladas na promoção da saúde. No entanto, pela especificidade do local, alguns projetos não se materializam: uma corda, por exemplo, pode se tornar um dispositivo de fuga ou ser usada como arma para tirar a própria vida ou a de outros. Uma corda é muito mais do que uma corda. Uma garrafa pet pode se transmutar em peso para exercícios físicos ou em um punhal. $\mathrm{O}$ enunciado expõe a impossibilidade de se negociarem possibilidades, mas também a marcação polissêmica e multifuncional dos artefatos discursivos e não discursivos.

Um dos entrevistados indica as ausências e a "real" situação de possibilidades de cuidado na prisão:

Melhorar a alimentação, dar recursos para o hospital e funcionários, dar exercício fisicico para os presos. Eles precisam de se exercitar, ser estimulados, dar informação para a pessoa não ficar sedentária. No banho de sol, alguns jogam futebol, mas, na real, é ficar na cela deitado, vendo televisão.

Sua fala remete a uma preocupação com sua saúde, inclusive com a saúde de outros homens que ali trabalham. Aponta que esse ambiente não é bom nem para quem ali trabalha. Entre "ser estimulado" a não ter uma vida sedentária e o que se faz "na real", nota-se a incorporação da discursividade da promoção da saúde, mas as marcações de uma série de limites que compõem a privação da liberdade.

\footnotetext{
"Teresa" é o termo utilizado pelos presos para se referirem a um dispositivo de fuga. Trata-se da amarração de várias cordas, que podem ser, inclusive, lençóis e toalhas, que pode ser arremessada para fora do pavilhão.
} 


\section{Considerações finais}

Consideramos que esta pesquisa aborda práticas e saberes em um campo ainda pouco explorado. Grande parte dos dados aqui discutidos remete a um homem generificado por modelos hegemônicos de masculinidades, marcado pela violência, avesso às práticas de cuidados e exposto à doença e à dificuldade de acesso a serviços. Para além da condição de serem homens, a "vida louca" justapóe vulnerabilidades variadas, dificilmente explicáveis apenas com os dados epidemiológicos habitualmente desenhados no contexto da PNAISH.

Em relação ao objeto de investigação, no qual se pretendia identificar as produções discursivas a respeito de saúde/doença expressos pelos homens presos, foi possível encontrar certa polissemia entremeada nos modos de compreender a saúde e como essas construçôes trazem ressonâncias nos modos de lidar com os próprios cuidados. Algumas falas que remetem às discussões sobre promoção da saúde desmontam a impressão de que a pessoa que está presa só cumpre pena. Há sentidos que deslocam as configurações habituais sobre o que é entendido como "risco" para esse grupo populacional e o que pode ser pensado como "cuidado". Há certo questionamento sobre a própria condição de estarem privados de liberdade e a construção de estratégias de resistência na produção de cuidados.

Ressalta-se a necessidade de avançar nesta temática, pois este trabalho pretende se somar aos conhecimentos sobre a saúde de homens presos e suas interfaces. Um elemento importante, inexplorado neste estudo, mas visibilizado por ele, é que existem outros homens envolvidos naquele cenário. Entre eles, os agentes de segurança penitenciários, diretores, juízes, policiais militares, advogados e outros técnicos, identificando-se como necessidade premente a realização de investigações que explorem as dimensões relacionais nesse contexto, seja como foco na saúde ou em outros aspectos.

\section{Referências}

Akerman, M. (2005). Saúde e desenvolvimento local: princípios, conceitos, práticas e cooperação técnica. São Paulo: Hucitec.

Brasil (2009a). Ministério da Justiça. Departamento Penitenciário Nacional. População privada de liberdade. Brasília: Ministério da Justiça. Recuperado a partir de: http://portal.mj.gov.br/data/Pages/MJC4D50EDBPTBRNN. htm 
Brasil. (2001). Ministério da Saúde. Carta de Ottawa. In Brasil. Ministério da Saúde. Promoção da Saúde. (pp. 19-24). Brasília: Ministério da Saúde.

Brasil. (2008). Ministério da Saúde. Secretaria de Atenção à Saúde. Departamento de Ações Programáticas Estratégicas. Política Nacional de Atenção Integral à Saúde do Homem: princípios e diretrizes. Brasília: Ministério da Saúde. Recuperado a partir de http://www.unfpa.org.br/Arquivos/ saude_do_homem.pdf.

Brasil. (2006). Ministério da Saúde. Secretaria de Vigilância em Saúde. Política Nacional de Promoção da Saúde. Brasília: Ministério da Saúde. (Série B. Textos Básicos de Saúde). Recuperado a partir de http://bvsms.saude.gov. br/bvs/publicacoes/politica_nacional_promocao_saude_3ed.pdf.

Brasil (2009b). Ministério da Saúde. Secretaria de Atenção à Saúde. Departamento de Ações Programáticas Estratégicas. Plano de Ação Nacional 2009-2011 da Política Nacional de Atenção Integral à Saúde do Homem. (2009). Brasília: Ministério da Saúde. Recuperado a partir de: http://bvsms. saude.gov.br/bvs/palestras/politica_atencao_integral_saude_homem.pdf.

Butler, J. (2003). Problemas de gênero: feminismo e subversão da identidade. Rio de Janeiro: Civilização Brasileira.

Carvalho, S. R. de. (2004). As contradiçõos da promoção da saúde em relação à produção de sujeitos e a mudança social. Ciência \& Saúde Coletiva, 9(3),669678. Recuperado a partir de: http://www.scielo.br/scielo.php?script=sci_ arttext\&pid=S1413-81232004000300018\&lng=pt\&nrm=iso\&tlng=pt.

Carrara, S., Russo, J. \& Faro, L. (2009). A política de atenção à saúde do homem no Brasil: os paradoxos da medicalização do corpo masculino. Physis Revista de Saúde Coletiva, 19(3), 659-678. Recuperado a partir de: http://www. scielo.br/scielo.php?script=sci_arttext\&pid=S0103-73312009000300006 \&lng=pt\&n rm=iso\&tlng=pt.

Castiel, L. D. (2007, julho-dezembro). Identidades sob risco ou risco como identidade? A saúde dos jovens e a vida contemporânea. Revista Interdisciplinar INTERthesis, 4, 2-16. Recuperado a partir de https:// periodicos.ufsc.br/index.php/interthesis/article/download/621/10857.

Castiel, L. D. (2012, julho-dezembro). Utopia/Atopia - Alma Ata, Saúde Pública e o "Cazaquistão". Revista Interdisciplinar INTERthesis, 9, 2-16. Recuperado a partir de: https://periodicos.ufsc.br/index.php/interthesis/ 
article/download/1807-1384.2012v9n2p62/23515.

Castiel, L. D. \& Silva, P. R. (2006). A noção de "estilo de vida" em promoção de saúde: um exercício crítico de sensibilidade epistemológica. In M. Bagrichevsky (Org.), A saúde em debate na Educação Física (pp. 67-92). Blumenau: Nova Letra. Recuperado a partir de http://boletimef.org/ biblioteca/2544/saude-em-debate-na-educacao-fisica-v-2.

Figueiredo, W. S. (2008). Masculinidades e cuidado: diversidade e necessidades de saúde dos homens na atenção primária. (Tese de Doutorado). Universidade de São Paulo, Programa de Pós-Graduação em Medicina, São Paulo.

Foucault, M. (1996). A verdade e as formas jurídicas. Rio de Janeiro: Nau.

Gois, S. M., Santos Junior, H. P. O., Silveira, M. de F. A. I. \& Gaudêncio, M de P. (2012). Para além das grades e punições: uma revisão sistemática sobre a saúde penitenciária. Ciência \& Saúde Coletiva, 17(5), 1235-1246. Recuperado a partir de: http://www.scielosp.org/scielo.php?script=sci_ arttext\&pid=S1413-81232012000500017\&lng=pt\&nrm=iso\&tlng=pt.

Gomes, R. \& Nascimento, E. F. (2006). A produção do conhecimento da saúde pública sobre a relação homem-saúde: uma revisão bibliográfica. Caderno de Saúde Pública, 22(5), 901-911. Recuperado a partir de: http:// www.scielo.br/pdf/csp/v22n5/03.pdf.

Gomes, R., Nascimento, E. F. \& Araújo, F. C. (2007). Por que os homens buscam menos os serviços de saúde do que as mulheres? As explicações de homens com baixa escolaridade e homens com ensino superior. Cadernos de Saúde Pública, 23 (3), 565-574. Recuperado a partir de: http://www.scielo. br/scielo.php?script=sci_arttext\&pid=S0102-311X2007000300015.

Medrado, B., Lyra, J., Valente, M., Azevedo, M. \& Noca, J. (2011). A construção de uma Política Nacional de Atenção Integral à Saúde do Homem. In Z. A. Trindade, M. C. S. Menandro \& C. R. R. Nascimento (Orgs.), Masculinidades e práticas de saúde (pp. 27-36). Vitória: GM.

Müller, R. F. (2012). Violência, vulnerabilidade e risco na política nacional de atenção integral à saúde do homem. Revista Epos, 3(2), 1-15. Recuperado a partir de: http://revistaepos.org/arquivos/06/RitaFlores.pdf.

Reigota, M. (1996). Narrativas ficcionais da práxis ecologista. In C. M Nascimento Schulze (Org.), Novas contribuiçôes para a teorização e pesquisa em representação social (pp. 47-58). Rio de Janeiro: Associação Nacional 
de Pesquisa e Pós-Graduação em Psicologia. (Coletâneas da Anpepp). Recuperado a partir de: http://www.infocien.org/Interface/Colets/ v01n10a005.pdf.

Quirino, T. R. L. (2012). A produção de cuidados no cotidiano de um serviço de atenção à saúde do homem. (Dissertação de Mestrado). Universidade Federal de Pernambuco, Programa de Pós-Graduação em Psicologia. Pernambuco.

Souza, E. R. (2005, janeiro-março). Masculinidade e violência no Brasil: contribuições para a reflexão no campo da saúde. Ciência \& Saúde Coletiva, 10 (1), 59-70. Recuperado a partir de: http://www.scielo.br/scielo. php?script=sci_arttext\&pid=S1413-81232005000100012.

Spink, M. J. \& Medrado, B. (1999). Produção de sentidos no cotidiano: uma abordagem teórico-metodológica para análise das práticas discursivas. In M. J. Spink (Org.), Práticas discursivas e produção de sentidos no cotidiano: aproximaçôes teóricas e metodológicas (pp. 41-62). São Paulo: Cortez. 